\title{
Exploring Attitudes toward Ecology through Documentaries
}

\author{
Mingfeng Yang1, Yanlin Li ${ }^{1,2 *}$ \\ ${ }^{1}$ School of Foreign Languages, Central South University, Changsha 410083, China \\ ${ }^{2}$ Department of Humanities, Xiangtan Institute of Technology, Xiangtan 411105, China \\ *Corresponding author: Yanlin Li, cstdxy2008@126.com
}

\begin{abstract}
The expanding development of the world economy has triggered various approaches to address the impending environmental problems, among which documentary serves as one of the most effective and attractive ways to cultivate ecoharmony awareness. This article aims to probe how attitudinal resources are being distributed and what Sino-British ideologies have conveyed in the Chinese documentary, Wild China, and the British documentary, Climate Change: The Facts, under the framework of appraisal theory with the help of UAM CorpusTool 3.3. The results from this study indicate that Wild China tends to employ more dis/inclination resources to show that China is willful to collaborate with other countries for environmental protection. On the other hand, the United Kingdom (UK) tends to adopt dis/satisfaction resources to explicitly or implicitly convey their disagreement with the promotion of the economy under the cost of the environment. The appraisal resources employed by both documentaries convey the ideology of opposing humans' over-exploitation of natural resources. The findings of this study have both theoretical and practical implications in enriching the application of appraisal theory on the analysis of ecological discourse and further encourage the world to take action in order to prevent the over-exploitation of natural resources.
\end{abstract}

Keywords: Appraisal theory; Attitudinal resources; Ecological discourse analysis; Wild China; Climate Change: The Facts

Publication date: September 2021; Online publication: September 30, 2021

\section{Introduction}

The term "ecological discourse analysis" was first introduced by Alexander and Stibbe in their article, "From the Analysis of Ecological Discourse to the Ecological Analysis of Discourse [1]." That is to say, EDA or ecological discourse analysis, was historically developed out of the analysis of ecological discourse, whose origin can be traced back to the famous speech given by Halliday in 1990.

Evoked by Halliday, an increasing number of scholars have taken up the challenge by drawing extensive attention to environmental discourse. For instance, Erica and Burman investigated environmental discourse from a feminist stance and dug out the radical potential of eco-feminism ${ }^{[2]}$. Browne and Keil studied the discourse of environmentalism in terms of lexical resources, grammatical aspects, temporal respects, and metaphoric usage ${ }^{[3]}$. Gerbig employed a corpus-based approach to the patterns of language used in environmental discourse ${ }^{[4]}$. Alexander and Stibbe explored various kinds of environmental discourse and divided them into four major categories: survivalism, environmental solving, sustainability, and green radicalism ${ }^{[1]}$. Mufwene commented that it is of necessity to make inquiries into how environmental matters are talked about, which is an indispensable component in solving environmental issues ${ }^{[5]}$.

As a transdisciplinary research program, EDA is not a single method of discourse analysis; rather, it is a group of multiple approaches, each with distinct but potentially overlapping methods ${ }^{[6]}$. As a theory with 
its consistent dedication to constructing a grammar for purposes of discourse analysis, systemic functional linguistics (SFL) along with its specific theories like transitivity and appraisal theory, provide an insightful theoretical basis for EDA.

The appraisal theory of SFL is a widely discussed topic within EDA. Based on Martin and White's appraisal theory ${ }^{[7]}$, Andrea analyzed a corpus of 40 multisemiotic news story in terms of evaluative meanings in heading, image, and caption ${ }^{[8]}$. According to the findings, he concluded that the existing appraisal system is not sufficient to describe the natural phenomenon in that the currently recognized subcategories of subsystems such as appreciation and graduation cannot fit in the evaluation of environmental events; thus, he put forth a new appraisal system by adding several other subcategories to Martin and White's version. For example, in the light of attitude subcategory, the kind of evaluation identified in the data saliently belongs to the subsystem of appreciation, which is with respect to the evaluation of things involving natural phenomena. However, Martin and White's appreciation subcategory includes reaction, composition, and valuation, none of which can be used to evaluate the environmental events in accordance with their effects ${ }^{[7]}$. Hence, a further subcategory, Effect, was suggested for the new appreciation system. Several scholars have made inquiries on the ecological assessment reports about silver hake and tried to construct the identity of nonhuman animals from the three strata within SFL: context, semantics, and lexico-grammar.

To add up, ecological discourse studies were mostly conducted from the perspective of systemic functional linguistics and critical discourse analysis, aiming to study the relationship between language and ecology. However, only a few studies have investigated the attitude or emotion in documentary discourse. This article attempts to analyze the two countries' appraisal resources under the framework of appraisal theory, aiming to discover how users can employ appraisal resources to achieve their ecological purposes.

\section{Research methodology}

\subsection{Research texts}

This article had selected the transcribed subtitles of the British documentary, Climate Change: The Facts, and the Chinese documentary, Wild China, as the research data. The British documentary, Climate Change: The Facts, with a 60-minute film length was first broadcasted in 2019 and produced by the British Broadcasting Corporation (BBC), delivering an unflinching exploration of what dangerous levels of climate change could mean for the human population as well as what is likely to happen if global warming exceeds 1.5 degrees and if major reductions in carbon dioxide $\left(\mathrm{CO}_{2}\right)$ emissions are not made in the next decade. The documentary observes potential solutions and exploration of innovations, technology, and actions the world's governments and industries are taking to prevent further warming, as well as showcasing individuals who are creating change at grassroots levels. In contrast, the Chinese documentary, Wild China, is the first large-scale TV documentary which reveals China's natural and cultural landscape. It is the first joint production by China Central Television (CCTV) and BBC, which begins from the hometown of rice in the south of the Yangtze River to the Xishuangbanna rainforest, the extremely cold Mount Everest, the Great Wall, which is the symbol of China, the Yellow River Basin, the birthplace of Chinese culture, and the winding $18000 \mathrm{~km}$ coastline.

Therefore, both documentaries can be regarded as representative of the two countries in consideration of their influences. Besides, the ecological discourses applied in the two documentaries provide equal access to everyone to apprentice in an ecological discourse community, serve as an essential approach to the research of both ecolinguistics and discourse analysis, and would further contribute to environmental protection. 


\subsection{Hypothesis on appreciation resources}

This study was conducted to analyze the ecological discourses from the two documentaries within the framework of appraisal theory. It aimed to find out how resources of attitude are construed in the texts, the factors contributing to the distribution of the attitudinal resources, as well as the Sino-British ideologies conveyed in the two documentaries.

Specifically, this article tried to explore the similarities and differences in the use of attitudinal words and sentimentality based on the analysis of the distribution of sub-resources within the attitude system in the Chinese and British ecological documentaries. Based on references and daily reading, Chinese mainstream media holds a positive and optimistic attitude toward future environmental development, while British mainstream media exaggerates the ability to "challenge" nature. Therefore, it has been assumed that the Chinese documentary, Wild China, uses more appreciative words with personal emotions compared to the British one.

\subsection{Data collection}

Data collection is of great significance for the purpose of achieving convincing results. This study is corpusbased, and the research samples have been chosen from the transcribed subtitles from two documentaries: the Chinese documentary, Wild China, and the British documentary, Climate Change: The Facts.

As mentioned in the introduction, the two documentaries can be regarded as representatives of the natural ideologies conveyed by China and UK. The ecological awareness applied in the two documentaries allows audiences to apprentice in an ecological discourse community, serving as an essential approach to the research of the synergy between cross-disciplinary research and discourse analysis. All in all, there are 13,221 words transcribed from the Chinese documentary, Wild China, and 10,018 words from the British documentary, Climate Change: The Facts. Therefore, the total number of the two data are similar, and they share the same topic - nature; thus, the objectivity of the research can be ensured.

\subsection{Research instrument: UAM CorpusTool 3.3}

This study has applied the appraisal theory to analyze the ecological discourse demonstrated in both documentaries. In this study, both the quantitative and qualitative analyzing methods have been employed. The qualitative analyzing method was employed to define what are the appraisal resources in the two documentaries in order to help translate the complex discourse content and provide a good foundation for the following detailed analysis. Quantitative analysis was used to calculate the data via statistics. UAM CorpusTool 3.3 was adopted in this study for accurate analysis. It is more powerful to validate the results of the data in a simplified and direct way. Figure 1 shows the operation window of the tool.

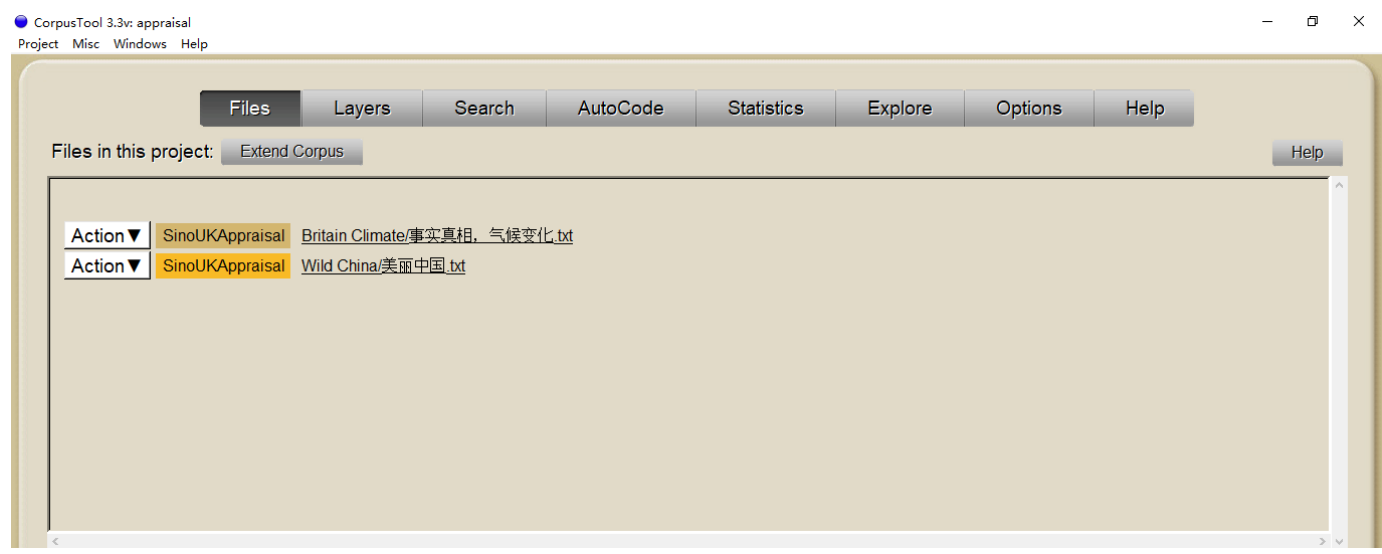

Figure 1. Project management pane 
UAM Corpus Tool 3.3 was research instrument applied in this study. Michael O'Donnell who developed the tool made a great contribution in providing people with a user-friendly software to assist in the annotation of texts. Users are allowed to apply tags to various segments of a particular text with the help of UAM CorpusTool 3.3. It can be downloaded from the website, www.wagsoft.com, for free. There are eight windows in the management pane.

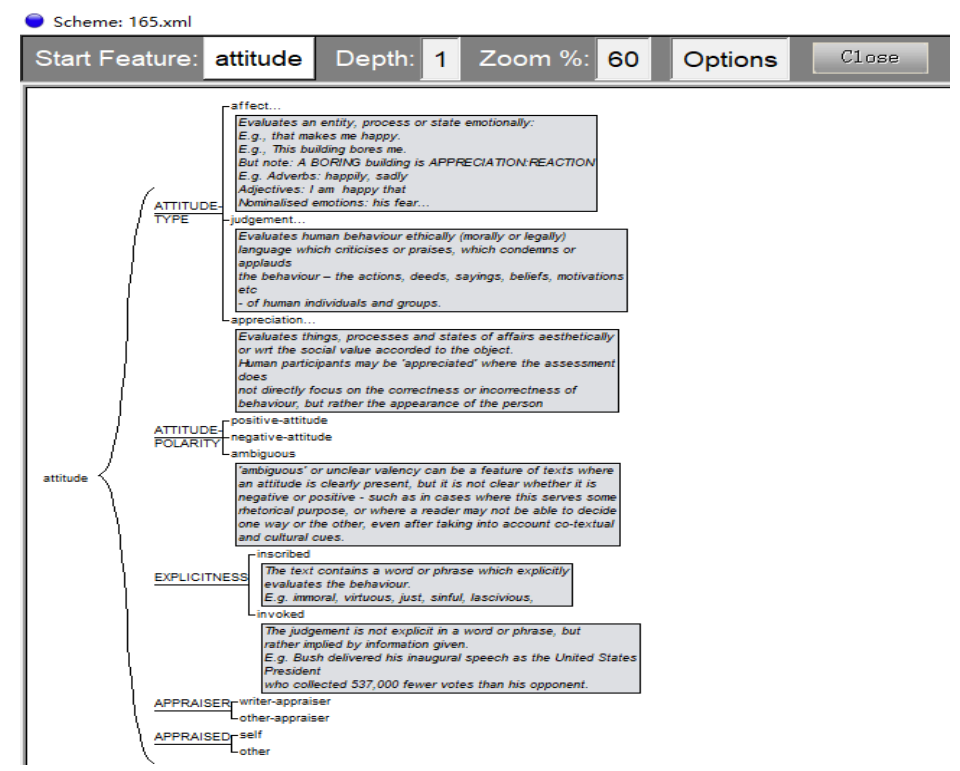

Figure 2. The scheme: Attitude

Two files have been added to the "Files" window for the ecological analysis in this study. The selected British documentary and Chinese documentary in English have been added separately to this window. All files that have been annotated here are in the TXT format. Layers decide what kind of analysis the study would perform. When a layer is added, the layer can be named based on an individual's personal preference. In manual annotation, the scheme is divided into the built-in scheme (Figure 2) and the user-specified scheme. The affect scheme adopted in this study is demonstrated in Figure 3.

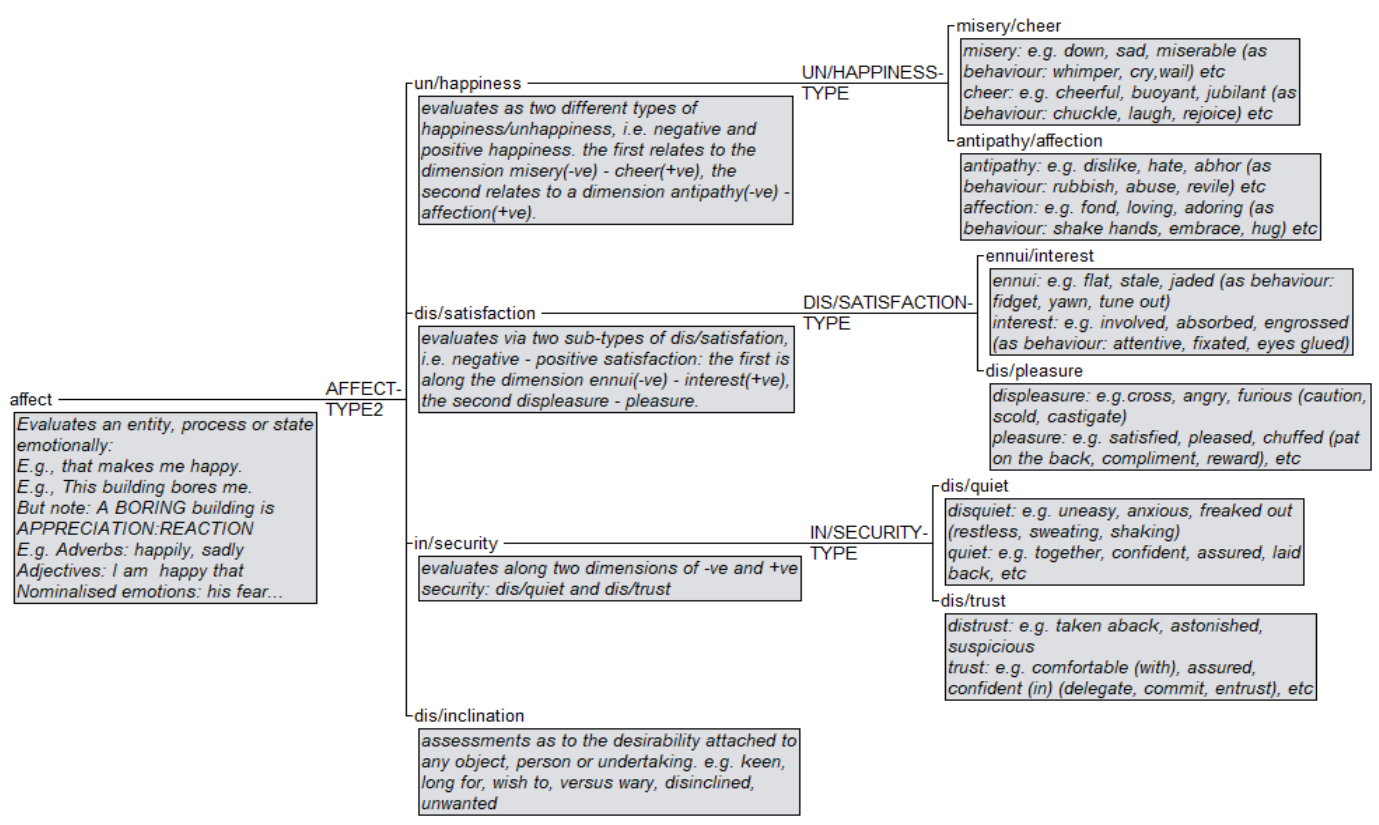

Figure 3. The scheme: affect (one of the subsystems of attitude) 
When the Search window is clicked, certain forms need to be settled to search for the desired word. The auto code window can code certain features of the files. For example, it is possible to annotate grammatical patterns of texts. It is also possible to add, edit, or delete the rules. The statistics results of the corpus will be demonstrated in the "Statistics" window. Different visualizing patterns in the corpora are displayed in the "Explore" window. The "Options" window shows the options of the corpus that can be chosen. The "Help" window offers users directions to conduct the study, and it has many topics about the operation of this software, especially when there are difficulties in using the software, users can resort to this window.

\subsection{Research procedure}

A synergy of qualitative and quantitative is established to maintain reliability and validity. The quantitative analysis is carried out to show the statistics from the UAM CorpusTool and the differences in distributions of appraisal resources. The qualitative analysis is applied by Martin's appraisal framework that mainly focuses on the features and differences of the interpersonal meaning of appraisal resources and the causes of differences in interpersonal meaning. This research was conducted according to the following procedures: First, the two documentaries were downloaded from the official websites, and the subtitles were transcribed into texts. Then, a scheme was set for the analysis under the guidance of the appraisal theory, and the two documentaries were added to the UAM CorpusTool 3.3.

Second, each documentary was analyzed and annotated according to the classifications and realizations of attitudinal resources. The distributions of attitudinal resources were presented, and the statistical results were demonstrated in table form. After obtaining the results in the UAM Corpus and combing with Excel, the analysis was continued to find out the distribution and characteristics of the attitudinal resources as well as the enlightenment of Sino-British's political position and political views.

The final step was to conduct a comparative analysis of the distributions and frequencies of the attitudinal resources. The similarities and differences of the statistics between the Chinese documentary and the British one were explained. In addition, with regard to the comparative analysis of subsystems of attitudinal resources employed by the two countries, concrete and typical examples excerpted from the data released by the two documentaries were explained to support the two countries' attitudes toward nature.

Quantitative analysis and qualitative analysis were the main research methods for this study. The qualitative analysis was based on the results of quantitative analysis. The data results helped to complete the textual analysis. With the help of the UAM CorpusTool 3.3, the data processing became more convenient and accurate. The reasons for the differences and imbalance of the appraisal resources would be summarized in the following section.

\section{Results}

Through annotation with the assistance of UAM CorpusTool 3.3, resources of affect, judgment, and appreciation have been identified and demonstrated in the form of data. This section presents and describes the results in the distribution and employment of the appraisal resources in the two documentaries.

\subsection{Distribution and employment of attitudinal resources}

The attitude system that embodies a speaker's values associated with emotional or affective responses to the judgment of participants or processes is in a key position in the appraisal theory ${ }^{[7]}$. In the subsystems, affect is the center of the attitudinal resources, which evaluates an entity, process, or state emotionally. Judgement evaluates human behavior morally or legally while appreciation evaluates things, processes, and states aesthetically or with the social value according to the object. 
There are 359 attitudinal resources generated from Wild China and 380 from Climate Change: The Facts. The overall distributions of attitudinal resources in CNN and Fox News are presented in Table 1.

Table 1. Attitudinal resources in Wild China and Climate Change: The Facts

\begin{tabular}{ccccc}
\hline \multirow{2}{*}{ Attitude } & \multicolumn{2}{c}{ Wild China } & \multicolumn{2}{c}{ Climate Change: The Facts } \\
\cline { 2 - 5 } & Number & Frequency (\%) & Number & Frequency (\%) \\
\hline Affect & 84 & 23.41 & 88 & 23.16 \\
Judgement & 80 & 22.28 & 132 & 34.74 \\
Appreciation & 195 & 54.32 & 160 & 42.11 \\
\hline
\end{tabular}

It can be seen from the table above that the distribution of the attitude system have different tendencies and frequencies between Wild China and Climate Change: The Facts. Specifically, in Wild China, the frequency of appreciation resources was the highest, accounting for 54.32\%. In Climate Change: The Facts, the frequency of appreciation resources was also the highest, accounting for $42.11 \%$, but $12.21 \%$ lower than that in Wild China. The frequency of affect resources ranked the second in Wild China, accounting for $23.41 \%$, which was $0.25 \%$ higher than the one in Climate Change: The Facts, accounting for $23.16 \%$. While in the British documentary, the frequency of judgement resources ranked second, accounting for $34.74 \%$, which was $12.46 \%$ higher than the one in China's, accounting for $22.28 \%$.

\subsection{Similarities and differences in the distribution of polarity and explicitness}

This section discusses the typical features such as explicitness and polarity of the attitudinal resources employed in the Chinese documentary and the British one. The statistics of explicitness and polarity of attitudinal resources are presented in Table 2.

Table 2. A Comparative distribution of attitudinal polarity and explicitness

\begin{tabular}{ccccccc}
\hline \multirow{2}{*}{ Feature } & \multicolumn{3}{c}{ Wild China } & \multicolumn{2}{c}{ Climate Change: The Facts } \\
\cline { 2 - 6 } & Number & \multicolumn{2}{c}{ Percentage } & Number & Percentage \\
\hline Polarity & & $\mathrm{N}=359$ & & & $\mathrm{~N}=380$ \\
Positive & 310 & & $86.35 \%$ & 120 & & $31.58 \%$ \\
Negative & 49 & & $13.65 \%$ & 260 & & $68.42 \%$ \\
Explicitness & & $\mathrm{N}=359$ & & & $\mathrm{~N}=380$ & \\
Inscribed & 252 & & $70.19 \%$ & 261 & & $68.68 \%$ \\
Invoked & 107 & & $29.81 \%$ & 119 & & $31.32 \%$ \\
\hline
\end{tabular}

From Table 2, it can be seen that there is an obvious difference in the polarity of attitudinal resources. In the Chinese documentary, there were 310 positive attitudinal resources with a proportion of $86.35 \%$ and 49 negative attitudinal resources with a proportion of $13.65 \%$. Therefore, the positive attitudinal resources prevailed over the negative ones. Contrary to Wild China, the negative attitudinal resources outnumbered the positive ones in Climate Change: The Facts. There were 120 positive attitudinal resources, accounting for $31.58 \%$ and 260 negative ones, accounting for $68.42 \%$. 


\subsection{Similarities and differences in the employment of affect}

Affect is at the heart of the attitude system. Writers or speakers employ affect resources to express the psychological reaction to behavior, text or process, and phenomenon ${ }^{[7]}$. It comprises of three subcategories, which are un/happiness, in/security, and dis/satisfaction. Besides, the concrete employment of each type of affect resources would be manifested. The statistics of subcategories of affect resources are displayed in Table 3.

Table 3. A comparative description of affect resources

\begin{tabular}{ccccccc}
\hline \multirow{2}{*}{ Feature } & \multicolumn{3}{c}{ Wild China } & \multicolumn{2}{c}{ Climate Change: The Facts } \\
\cline { 2 - 6 } & Number & & Percentage & Number & Percentage \\
\hline Affect & & $\mathrm{N}=84$ & & 8 & $\mathrm{~N}=88$ \\
Un/happiness & 9 & & $10.71 \%$ & $9.09 \%$ \\
Dis/satisfaction & 17 & & $20.24 \%$ & 27 & $30.68 \%$ \\
In/security & 34 & & $40.48 \%$ & 39 & & $44.32 \%$ \\
Dis/inclination & 24 & & $28.57 \%$ & 14 & & $15.91 \%$ \\
Un/happiness & & $\mathrm{N}=9$ & & & $\mathrm{~N}=8$ & \\
Misery/cheer & 2 & & $22.22 \%$ & 2 & & $25.00 \%$ \\
Antipathy/affection & 7 & & $77.77 \%$ & 6 & & $75.00 \%$ \\
Dis/satisfaction & & $\mathrm{N}=17$ & & & $\mathrm{~N}=27$ & \\
Ennui/interest & 4 & & $23.53 \%$ & 9 & & $33.33 \%$ \\
Dis/pleasure & 13 & & $76.47 \%$ & 18 & & $66.66 \%$ \\
In/security & & $\mathrm{N}=34$ & & & $\mathrm{~N}=39$ \\
Dis/quiet & 19 & & $55.88 \%$ & 25 & & $64.10 \%$ \\
Dis/trust & 15 & & $44.12 \%$ & 14 & & $35.90 \%$ \\
\hline
\end{tabular}

From Table 3, it can be seen that in Wild China, the number of un/happiness reached 9, amounting to a proportion of $10.71 \%$. Dis/satisfaction accounted for $20.24 \%$ with a total of 17 . In/security accounted for $40.48 \%$ with a value of 34 while dis/inclination reached 24 , amounting to a proportion of $28.57 \%$. Therefore, in/security was the most frequently used affect resource followed by dis/inclination, dis/satisfaction, and un/happiness. In regard to Climate Change: The Facts, in/security also took up the most significant proportion of affect resources followed by dis/satisfaction, dis/inclination, and un/happiness.

\subsection{Similarities and differences in the employment of judgement}

Judgement is involved with assessing behaviors, and it includes social esteem and social sanction ${ }^{[7]}$. Besides, the judgement system has a positive and a negative dimension. Moreover, the lexical item can be used to express explicit judgement such as corruptly, lazily, etc. Meanwhile, judgements can be evoked purely by factual descriptions. Based on the brief introduction of the judgement system, the statistics of judgement resources in the two documentaries selected from China and UK are shown in Table 4. 
Table 4. A comparative description of judgement resources

\begin{tabular}{|c|c|c|c|c|c|}
\hline \multirow{2}{*}{\multicolumn{2}{|c|}{ Feature }} & \multicolumn{2}{|c|}{ Wild China } & \multicolumn{2}{|c|}{ Climate Change: The Facts } \\
\hline & & Number & Percentage & Number & Percentage \\
\hline \multicolumn{2}{|c|}{ Judgement type } & \multicolumn{2}{|c|}{$\mathrm{N}=80$} & \multicolumn{2}{|c|}{$\mathrm{N}=132$} \\
\hline \multirow[t]{3}{*}{ Social esteem } & Normality & 6 & $7.50 \%$ & 5 & $3.79 \%$ \\
\hline & Capacity & 43 & $53.75 \%$ & 31 & $23.48 \%$ \\
\hline & Tenacity & 9 & $11.25 \%$ & 17 & $12.88 \%$ \\
\hline \multirow{2}{*}{$\begin{array}{c}\text { Social } \\
\text { sanction }\end{array}$} & Propriety & 15 & $18.75 \%$ & 67 & $50.75 \%$ \\
\hline & Veracity & 7 & $8.75 \%$ & 12 & $9.09 \%$ \\
\hline
\end{tabular}

Altogether, 80 instances were annotated in Wild China. Capacity resources obviously outweighed the others with a total of 43 , accounting for $53.75 \%$. There was no significant difference between tenacity and veracity resources. With respect to Climate Change: The Facts, there were 132 judgement resources employed in total. Propriety resources ranked the first with a total of 67 , accounting for $50.75 \%$. The value of capacity resources was 31 , which was nearly half of the propriety resources. Less than those, veracity resources reached 12 with a proportion of $9.09 \%$. Normality resources took up the least proportion which was $3.79 \%$ with 5 items.

\subsection{Similarities and differences in the employment of appreciation}

Appreciation is concerned with aesthetics, and it demonstrates diversified evaluations of natural objects and phenomena ${ }^{[7]}$. It has three subcategories, which are reaction, composition, and valuation. Similar to the affect and judgement system, the appreciation system also has an inscribed or invoked dimension. Table 5 displays the frequency and proportion of appreciation resources.

Table 5. A comparative description of appreciation resources

\begin{tabular}{ccccccc}
\hline \multirow{2}{*}{ Feature } & \multicolumn{3}{c}{ Wild China } & \multicolumn{2}{c}{ Climate Change: The Facts } \\
\cline { 2 - 6 } & Number & & Percentage & Number & Percentage \\
\hline Appreciation & & $\mathrm{N}=195$ & & 33 & $\mathrm{~N}=160$ \\
$\quad$ Reaction & 29 & & $14.87 \%$ & $20.63 \%$ \\
Composition & 50 & & $25.64 \%$ & 72 & & $45.00 \%$ \\
Valuation & 116 & & $59.49 \%$ & 55 & & $34.38 \%$ \\
Reaction & & $\mathrm{N}=29$ & & & $\mathrm{~N}=33$ & \\
Impact & 7 & & $24.14 \%$ & & & $24.24 \%$ \\
Quality & 12 & & $41.38 \%$ & & & $75.76 \%$ \\
Composition & & $\mathrm{N}=50$ & & & $\mathrm{~N}=72$ & \\
Balance & 44 & & $88.00 \%$ & 12 & & $16.67 \%$ \\
Complexity & 6 & & $12.00 \%$ & 60 & & $83.33 \%$ \\
\hline
\end{tabular}

From Table 5, it is obvious that the number of appreciation resources in Wild China outweighed the number in Climate Change: The Facts by quite an amount. Apart from this difference, the subsystems of appreciation resources employed by both documentaries also differed from each other. Valuation resources with a number of 116 employed by Wild China outnumbered the ones employed by the British with 55 . The most frequently used appreciation resource in Climate Change: The Facts was composition. Besides, obvious differences in the subcategories of composition resources can be noted, where more complexity 
resources were found in Climate Change: The Facts than balance resources, with a contrary situation in Wild China.

\section{Discussion}

As the carrier of culture, discourse does not only embody the connotation of culture, but also affect the evaluation process. Evaluation is a complex cognitive process, consisting of several different elements, each of which is an indivisible part of unity.

The determination of evaluation criteria has always been restricted by the appraisers' discourse roles, point of view, ideology, and values. Hence, evaluations are not always objective, explaining the contrastive analysis in the above part, which reveals the fact that different countries make different evaluations on the same topic. This section explores the reasons of the different attitudinal meanings conveyed by China and Britain in Wild China and Climate Change on ecological issues, respectively.

\subsection{Discourse roles}

The different discourse roles that countries play in ecological discourse can explain why there are differences in alignment between affect (Table 3), judgement (Table 4), and appreciation (Table 5) resources in Wild China and Climate Change.

The discourse roles that countries play in the documentaries can be divided into three types: involver, organizer, and observer. As an involver in ecological discourse, the first person often plays the role of reporting and narrating events directly. The involver aims to increase the credibility of the report, but it would also decrease the objectivity of the report. The organizer in ecological discourse conveys the will of social groups who play the main role in the process of evaluation. The observer in ecological discourse makes evaluations to the discourse itself and to a lesser extent, participating in the evaluation of referenced views. In ecological discourse, if appraisers are directly involved in the discourse as an involver, the discourse is often subjective. In documentaries and other news media, appraisers often play the role involved in discourse in order to acknowledge the messages that have been reported and carry the responsibility for the reliability of the information. As an organizer, reporters are authorized to convey the will of authorities as the role of a speaker. The information conveyed by the observer is the evaluation of comments in the discourse.

Therefore, the appraiser in Wild China dedicates to play the role of an involver and also an observer in the ecological discourse about nature to convey the attitude and stance of authorities. In this way, the appreciation resources (as shown in Table 1) in Wild China takes the greatest amount, especially its positive attitude toward environment and human development. Wild China tends to include different voices to create a wider dialogical space and to avert the responsibility for the credibility of the information they report as well as the promising eco-harmonious future. By contrast, the British one plays the role of an organizer to directly narrate the pending ecological issues that would bring catastrophe to human beings. They prefer to exclude positive voices from their value position and to insist on their own standpoint, creating panic among humans and lacking the emphasis on the establishment of alignment with human and environment.

In summary, ecological discourse has a significant effect on revealing and construing society. For example, the appraisal resources employed in the two documentaries helped to reveal the state of the world's climate and water problems encountered in addition to the efforts made to deal with them. At the same time, the construed solutions with the employment of appraisal resources serve to provide ways in which the two countries can use to solve the problems in nature and attract the public's attention. In this way, the ecological discourse can, in turn, construe society. Therefore, the creation of ecological discourse should focus on encouraging ecological implications for a better-developed society. 


\subsection{Value orientation}

According to Table 3, it is obvious that the ecological discourses of the two countries share a similarity, of which in/security resources were most frequently employed. For example, words such as "concern," "skepticism," and "insecurity" are frequently used in the British documentary to display their negative attitudes toward the current situation of nature. By contrast, Wild China often reported authoritative standpoints with vivid examples like the Yangtze River to ensure the efforts made by China would further promote a win-win situation for both the economic progress and the conservation of natural resources. Besides, un/happiness resources were the least employed in both countries to avoid subjective feelings and judgments.

In terms of differences, other than in/security resources, Wild China employed more dis/inclination resources to show that China is willful to collaborate with other countries for environmental protection. Instead, UK adopted dis/satisfaction resources to explicitly or implicitly convey their disagreement with the promotion of economy while neglecting the environment. The differences in values may explain why in/security resources (as shown in Table 3) were preferred in both Wild China and Climate Change: The Facts.

Documentary, as a part of social media, is sufficiently associated with the public or special audiences to warrant press attention or coverage. People seem to be interested in media, describing conflicts, involving well-known people, and those deviating from the norms of everyday happenings, to the extent of having an essential impact. Therefore, the values that the media convey seem to be common across cultures. Among the list of values, the values of consonance and interest vary from different standpoints.

Consonance refers to the media's readiness to report an item relating to the directors' stereotypes and their mental scripts for how events typically proceed. On the other hand, interest refers to the relationship between facts and the audiences' psychological and emotional tendency to seek information, entertainment, novelty, as well as differences. The more interesting the discourse is, the more attention it would gain and the more valuable a particular text becomes; thus, interest is significant to media broadcasting in a rapidly evolving international market. Countries are increasingly concerned with the production of fruitful and relevant ideologies for the general public, and they have a greater awareness of the significance of discourse values presented on screen that would attract and retain audiences in order to have a status known to the world. This has led the media to attach great importance to the interest of countries as well as the desire of the citizens.

Climate Change: The Facts has been alleged as a biased documentary because it often reports information that is more favorable to human rather than taking nature into consideration. It has a tendency to issue negative propaganda in regard to the so-called "devastating future." In contrast, the aim of Wild China is to reveal the wonders of nature and the harmonious peace in the human-nature relationship. The ecological discourses reveal China's attitude in its commitment to take up the responsibility of protecting the environment and stopping aggressive exploitation in order to develop the economy.

\section{Conclusion}

Under the guidance of the appraisal theory, this study is a discourse analysis of two documentaries produced by China and Britain on ecological issues. Within the scheme of attitude system, the two documentaries have been annotated in terms of attitudinal resources with the help of UAM CorpusTool 3.3. Based on the annotation results of the appraisal resources, the distribution and employment of appraisal resources in the two documentaries were analyzed and presented, followed by a discussion of the factors contributing to the distribution of the appraisal resources, and finally, the generalization of the ideologies conveyed in the two documentaries. 


\subsection{Similarities and differences of Sino-British attitudinal resources in EDA}

In terms of the similarities of the distributions of attitudinal resources in the ecological discourses in Wild China and Climate Change: The Facts, there are three features. Firstly, both the ecological discourses presented in Wild China and Climate Change: The Facts have more emphasis on appreciation rather than judgment in regard to natural resources. Secondly, both the documentaries highlight the objectivity of their discourses as they tend to quote interviewees' opinions in order to attribute their views. Third, the two countries attach importance to the adjustment of attitude strength. They tend to adjust their attitudes on environmental protection to meet the needs of their own ideologies during broadcasts.

On the other hand, with respect for the differences in attitudinal resources in the research texts, there are two major differences based on the contrastive analysis of the distribution of each appraisal resource. One of the differences is in the attitude and stance, whereas the other is in the alignment between human and environment.

In consideration of attitude and stance, the discourses of Wild China implied a more positive and optimistic attitude. In addition, its attitude and stance are more exact and stronger. The texts in the British documentary expressed more negative and pessimistic attitude on natural resources conservation while its attitude and stance are more vague and weak on the whole. In consideration of the alignment between human and environment, the ecological documentary of Climate Change focuses more on the persuasion of the public under a potential threat of a devastating future; however, Wild China tends to highlight the description of objective information and use current examples to consolidate the inner awareness of environmental protection among the general public.

\subsection{Practical (corpus-based) and theoretical (AT) implications}

This research is of great innovation theoretically and practically. This research aimed to investigate documentaries under the guidance of the synergy of appraisal theory (AT) and ecological discourse analysis (EDA), and it managed to achieve objective and thought-provoking results. Under the guidance of EDA, the subjectivity caused by the elusive application of the appraisal theory in ecological discourse analysis decreases to some extent. Furthermore, this research has confirmed that the appraisal theory, developed out of SFL, is also feasible to be an analytical tool for studies on media discourse from an EDA perspective because they both focus on the exploration of interpersonal meaning. Therefore, this research can shed light on innovations in the application of linguistic theories and attract further studies on ecological discourse in relation to the environment from other perspectives and theories.

Practically, this research employed a corpus-based method to confirm that documentary makers are inclined to apply different attitudinal resources to convey their attitudes in order to serve their underlying ideologies. Therefore, through data analysis, the results and appraisal employment of the two documentaries can instigate the exploration of environmental awareness in both China and the UK. Moreover, this research enlightens the audiences to form a habit of critical reading in order to grasp the ideologies conveyed by media resources and have a right perception of the world rather than being totally controlled or misguided by the mass media. Furthermore, the different appraisal approaches by China and the UK in broadcasting ecological issues can provide enlightenment for other countries.

\section{Funding}

This study was financially supported by the Fundamental Research Funds for the Central Universities of Central South University, (Grant Number: 1053320210469). 


\section{Disclosure statement}

The authors declare that there is no conflict of interest.

\section{References}

[1] Alexander RJ, Stibbe A, 2014, From the Analysis of Ecological Discourse to the Ecological Analysis of Discourse. Language Sciences, 41: 104-110.

[2] Erica, Burman, 1992, Identification and Power in Feminist Therapy: A Reflexive History of a Discourse Analysis. Women's Studies International Forum, 15(4); 487-498.

[3] Browne DR, Keil R, 2000, Planning Ecology: The Discourse of Environmental Policy Making in Los Angeles. Organization \& Environment, 13(2): 158-205.

[4] Gerbig DG, Fenk CJ, Grooms SY, 2000, A Convenient and Highly Specific Western Blot Experiment for Introductory Biochemistry. Journal of Chemical Education, 77(3): 373.

[5] Mufwene SS, 2017, Language Evolution from an Ecological Perspective, in Fill A, Penz H, (eds), The Routledge Handbook of Ecolinguistics, Routledge, London, 73-88.

[6] Bang JC, Trampe W, 2014, Aspects of an Ecological Theory of Language. Language Sciences, 41: 8392.

[7] Martin JR, White PRR, 2005, The Language of Evaluation: Appraisal in English, Palgrave Macmillan, New York.

[8] Sedlaczek AS, 2016, Representations of Climate Change in Documentary Television. Integrating an Ecolinguistic and Ecosemiotic Perspective into a Multimodal Critical Discourse Analysis, Language \& Ecology, 24-26.

[9] Agnes M, 2014, Flavors of Appraisal Theories of Emotion. Emotion Review, 6: 303-307.

[10] Alexander RJ, 2017, Investigating Texts About Environmental Degradation Using Critical Discourse Analysis and Corpus Linguistic Techniques, in Fill A, Penz H, (eds), The Routledge Handbook of Ecolinguistics, Routledge, New York and London, 196-210.

[11] Anné E, 2020, An Appraisal Theory Approach to News Reports on Rhino Poaching in South Africa. Language Matters, 1: 86-112.

[12] Biber D, Finegan E, 1989, Styles of Stance in English: Lexical and Grammatical Marking of Evidentiality and Affect. Text - Interdisciplinary Journal for the Study of Discourse, 9(1).

[13] Ellsworth PC, 2013, Appraisal Theory: Old and New Questions. Emotion Review, 5(2): 125-131.

[14] Fuoli M, 2012, Assessing Social Responsibility: A Quantitative Analysis of Appraisal in BP's and IKEA's Social Reports. Discourse and Communication, 6(1): 55-81.

[15] Gallardo S, Ferrari L, 2010, How Doctors View Their Health and Professional Practice: An Appraisal Analysis of Medical Discourse. Journal of Pragmatics, 42(12): 3172-3187.

[16] Grundlingh L, 2018, Exploring the Possibility of Using Appraisal Theory to Determine the Legitimacy of Suicide Notes. Lingua, 214: 1-10.

[17] Korenek P, Simko M, 2014, Sentiment Analysis on Microblog Utilizing Appraisal Theory. World Wide Web-Internet \& Web Information Systems, 17(4): 847-867.

[18] Martin JR, 2000, Beyond Exchange: Appraisal system in English: In Evaluation in Text. Oxford University Press, Oxford.

[19] Painter C, 2003, Developing Attitude: An Onto-Genetic Perspective on Appraisal. Text, 23(2): 211 237. 
[20] Page R, 2003, An Analysis of Appraisal in Childbirth Narratives with Special Consideration of Gender and Storytelling Style. Text, 23(2): 211-237.

[21] Roseman IJ, 2013, Appraisal in the Emotion System: Coherence in Strategies for Coping. Emotion Review, 5: 141-149.

[22] Tavassoli F, Jalilifar A, White PRR, 2019, British Newspapers' Stance towards the Syrian Refugee Crisis: An Appraisal Model Study. Discourse and Society, 30(1): 64-84.

[23] $\mathrm{Hu} \mathrm{Z}, 2009$, The Appraisal Research of Discourse. Foreign Language Education, 30(1): 1-6.

[24] Li Z, 2004, Appraisal Theory: Applications and Problems in Discourse Analysis. Foreign Language Research, 21(5): 1-6.

[25] Liu S, Zhang Z, 2004, Structural Potential and Semantic Configuration of Appraisal. The Journal of Foreign Languages in China, 8(1): 22-27.

[26] Ma W, 2007, The enlightenment of Appraisal Theory on oral English Teaching. Foreign Language Education, 28(6): 37-40.

[27] Wang M, 2017, A Study on College English Majors'Writings from the Perspective of Appraisal Theory. Theory and Practice in Language Studies, 7(1): 65-69.

[28] Zhang M, 2002, The Appraisal Meaning of Languages and Value Orientation of Translators. Foreign Languages and Their Teaching, 18(7): 15-18. 